\title{
Case Report of Bilateral Medial Rectii Recessions as a Surgical Modality in Cases of Bil Alternating Infantile Esotropia in 6 Months Old Male Twins
}

\author{
Gowhar Ahmad* \\ Department of Ophthalmology, University of Jammu and Kashmir, India \\ *Corresponding author: Gowhar Ahmad, Department of Ophthalmology, University of Jammu and Kashmir, India

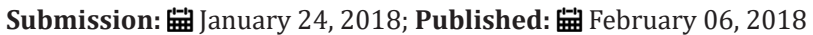

\begin{abstract}
Squint or strabismus is an ocular condition in which an eye deviated from its normal position of parallelism we have different forms of squints 1 con 2 acquires one of the most important things while dealing with a squint is to do the following things

1. Visual assessment

2. Refraction mydriatic

3. Fundus examination

Why funds as in children retinoblastoma and coats disease can present as squint urge we have got various forms of squint

1. Accommodate

2. Non Accommodative

11 paralytic non paralytic 11 concomitant non concomitant squint can be esotopia, exotropia, hypertropia, hypotripia, pseudotropia, hertrotropia, microtropia and cyclotropia.
\end{abstract}

\section{Introduction}

Bil alternating infantile tropia can present as

1. Crossed fixation

2. In crossed fixation

3. Av pattern

4. Broad angle

5. Over action of Inf oblique

6. Covering the dominant eye will make the child to cry

Case Report

6 months old twins were seen by me in 2002 with parents having noticed bil alternate inward ocular deviation since 3 months on examination both twins had 20 to 25 degrees bil alternating esotopia f t normally delivered children no other cong abnormalities present ocular movements full and within normal limits mydriatric refraction ant segment and fundii normal both twins no evidence of abnormal head posture or ocular torticolis so under gain both twins bil $5 \mathrm{~mm}$ medial rectii recessions was done after exposure of eye with eye sprculm rotation of eye balls was done with 6 zero silk sutures passed at 6 and 12 o clock positions respectively isoloation of medial rectii was done through limbal based conjuctival aproach $5 \mathrm{~mm}$ recessions of medial rectii was done and position of produces asatisfactory correction of angle of squint but it produces minimal eye reaction as in recession we do not cut muscle so reaction is less however there are few complications associated with this procedure not serious but they are as follows 1 under correction 21 amblyopia over action of inferior oblique medial rectii was secured on sclera using 6 zero vicoryl sutures then conjuctival reposition was done post operatively there was a very satisfactory correction of angle of squint with minimal eye reaction discussion medial rectii recessions for bil alt inf esotopia is a n operative modality of choice even after more than 15 years same procedure is done these days conclusion medial rectii recessions for bil alt esotopia not only produces a satisfactory correction of angle of squint but the eye reaction is minimal as in recessions as we do not cut muscles the eye reaction is minimal howevross few complicationser we do come ross few post operative complications as 
1. Under correction

2. Amblyopia

3. Over action of Inf. oblique

4. Accomodative element

5. DVD (Dessociated Verticle Deviation).

\section{Conclusion}

1. We have golden hars syndrome support group

2. There are families of golden hars syndrome such 17 families are seen in Greece

3. Infants born in gulf middle east in different military hospital were having golden hars syndrome

\section{Mittal et al. in Indian journal of ophthalmology}

1968 reported 3 cases of optic nerve head drusens associated with $\mathrm{g} \mathrm{h} \mathrm{s}$ in some rare ceases of $\mathrm{g} \mathrm{h} \mathrm{s}$ if there is facial asymmetry or hare lip cleft palate one has to get the consultation of plastic surgeon and this may need plastic repair also in some cases pre auricular appendages are also corrected by plastic surgeon In ophthalmic article of rare and interesting case of Goldenhars syndrome in 3 years old child.

\section{References}

1. Hobot Wilner Z, A Glovinsky, J Wygnansia, Jafp T (2006) Bilateral M.Rectii muscle recession Results in children with develovemental delay compared with normally developed children. J AAPOS 10(2): 152-154. 